\title{
Temporal and spatial variation in sex-specific abundance of the avian vampire fly (Philornis downsi)
}

\author{
Lauren K. Common ${ }^{1}$ (D) Petra Sumasgutner ${ }^{2}$ (D) Shane C. Sumasgutner ${ }^{2} \cdot$ Diane Colombelli-Négrel $^{1} \mathbb{D}$. \\ Rachael Y. Dudaniec ${ }^{3}$ (i) . Sonia Kleindorfer ${ }^{1,2}$ (1)
}

Received: 28 July 2021 / Accepted: 12 October 2021 / Published online: 20 November 2021

(c) The Author(s) 2021

\begin{abstract}
Understanding the range and behaviour of an invasive species is critical to identify key habitat areas to focus control efforts. Patterns of range use in parasites can differ temporally, across life stages and between sexes. The invasive avian vampire fly, Philornis downsi, spends the larval stage of its life within bird nests, feeding on developing nestlings and causing high levels of mortality and deformation. However, little is known of the ecology and behaviour of the non-parasitic adult fly life stage. Here, we document sex-specific temporal and spatial patterns of abundance of adult avian vampire flies during a single Darwin's finch breeding season. We analyse fly trapping data collected across 7 weeks in the highlands ( $N=405$ flies) and lowlands $(N=12$ flies) of Floreana Island (Galápagos). Lowland catches occurred later in the season, which supports the hypothesis that flies may migrate from the food-rich highlands to the food-poor lowlands once host breeding has commenced. Fly abundance was not correlated with host nesting density (oviposition site) but was correlated with distance to the agricultural zone (feeding site). We consistently caught more males closer to the agricultural zone and more females further away from the agricultural zone. These sex differences suggest that males may be defending or lekking at feeding sites in the agricultural zone for mating. This temporal and sex-specific habitat use of the avian vampire fly is relevant for developing targeted control methods and provides insight into the behavioural ecology of this introduced parasite on the Galápagos Archipelago.
\end{abstract}

Keywords Range use $\cdot$ Ectoparasite $\cdot$ Invasive species $\cdot$ Galápagos Islands $\cdot$ Philornis

\section{Introduction}

In an era of increasing human and animal global mobility, the proportion of invasive species is rapidly increasing, exacerbated by the effects of climate change, over-exploitation, pollution, and habitat fragmentation (Pelletier and

Section Editor: Elizabeth Marie Warburton

Sonia Kleindorfer

sonia.kleindorfer@univie.ac.at

Lauren K. Common

lauren.common@flinders.edu.au

1 College of Science and Engineering, Flinders University, Bedford Park, SA 5001, Australia

2 Konrad Lorenz Research Center, Core Facility for Behaviour and Cognition, Department of Behavioural and Cognitive Biology, University of Vienna, Vienna, Austria

3 Department of Biological Sciences, Macquarie University, Sydney, NSW 2109, Australia
Coltman 2018). Invasive parasites that pose risks to public health (González et al. 2017; Ruberanziza et al. 2019) or that negatively impact host species of conservation concern (Olson et al. 2013) warrant monitoring for informing control strategies. A single species may occupy and utilise different areas within its range across seasons, life stages, and between sexes (Bierzychudek and Eckhart 1988; Maxwell et al. 2019; Ruckstuhl and Neuhaus 2006). Understanding the distribution and behaviour of an introduced species is useful to identify seasonally or geospatially restricted habitat areas to focus control and management efforts (Escobar et al. 2019; Mathieu-Bégné et al. 2020; Raghavan et al. 2019; Woodworth et al. 2005).

In parasitic arthropods, studies have found selective spatial and temporal habitat use between the sexes (Papadopoulos et al. 2003; Sciarretta et al. 2018; Warburg and Yuval 1997; Wong and Jim 2018). In general, sexual conflict and sexual dimorphism have been shown to drive sex-specific distributions in arthropods (Foster and Soluk 2006; Romey and Wallace 2007; Stanley et al. 2018). Patterns of male and 
female abundance can differ due to sex-biased dispersal, with extremes where one sex disperses while the other is sedentary, which is especially relevant during range expansions or invasions (Beirinckx et al. 2006; Dudaniec et al. 2021; Miller and Inouye 2013). In other cases, females may aggregate together, away from areas of high male density, to avoid harassment from males, which is seen in systems with high costs to females from multiple mating (Roswell et al. 2019; Stanley et al. 2018; Stone 1995; Warburg and Yuval 1997). Understanding patterns of sex-specific distribution, location of oviposition, and feeding sites in invasive parasite populations is useful to control mating behaviours and frequencies, and to maximise the impact of targeted control interventions (Dunn and Hatcher 2015).

In resource-based mating, which is common in many insects, including parasitic insects (Dodson 1997; PrestonMafham 2001; Warburg and Yuval 1997; Wilkinson and Johns 2005), males compete to guard a resource, such as a food or oviposition site, and mate with females that are attracted to the resource (Choe and Crespi 1997; Parker 1978). Resources must be predictable and defendable but uncommon enough to attract females. When resources are scattered or ubiquitous, swarm-based mating or mate searching systems, where males actively search for receptive mates, tend to prevail (Emlen and Oring 1977; Wilkinson and Johns 2005). Defended resources differ across species and are commonly food or oviposition sites (PrestonMafham 2001; Wilkinson and Johns 2005). Males may lek near resources (Hendrichs et al. 1991; Warburg and Yuval 1997; Yuval 2005) or defend non-resource-based territories (Yeates and Dodson 1990) to attract and mate with females. Integrating information on the spatial and temporal distribution of invasive species, their mating systems, and monitoring of female population densities is therefore critical for the success of large-scale eradication programs (Enkerlin et al. 2017; Yamagishi et al. 1993).

The avian vampire fly (Philornis downsi, Dodge and Aitken, 1968) (Diptera: Muscidae) is a generalist invasive ectoparasite whose larvae consume the blood and tissue of developing birds across a range of host species (Dudaniec and Kleindorfer 2006; McNew and Clayton 2018). Introduced to the Galápagos Islands during the 1960s, avian vampire fly larvae were first discovered in Darwin's finch nests in 1997 (Causton et al. 2006; Fessl et al. 2001). Since then, the fly has been detected on 14 islands across the archipelago (Fessl et al. 2018; Wiedenfeld et al. 2007). Adult avian vampire flies are non-parasitic and feed on fruit, nectar, and decaying vegetable matter (Fessl et al. 2018). However, their larvae are obligate parasites of nestlings, feeding both internally and externally on the host (Fessl et al. 2006; O'Connor et al. 2010a). In its invasive range, the avian vampire fly is highly virulent, causing severe in-nest mortality or alternatively, naris deformation in nestlings that persist into adulthood and thus affect song and foraging technique (Kleindorfer et al. 2019; Kleindorfer and Dudaniec 2016; Kleindorfer et al. in review). The effects of avian vampire fly parasitism, such as lowered body condition, naris deformation, and mortality, are of particular concern for declining populations of critically endangered Darwin's finch species (Fessl et al. 2010; Lawson et al. 2017; O'Connor et al. 2010b).

Our understanding of adult avian vampire fly behaviour comes from genetic sources where multiple mating behaviour was established via larval sib-ship reconstructions (Dudaniec et al. 2010), or from video recordings at host nests that showed adult flies entering and leaving nests (Lincango et al. 2015; O'Connor et al. 2010a). Male and female avian vampire flies differ in their minimum longevity determined under laboratory rearing conditions (males $\sim 188$ days; females $\sim 265$ days) (Causton et al. 2019). The height at which adult flies were caught differed between the sexes on Floreana Island-females were more commonly caught at lowest and highest heights $(2 \mathrm{~m}$ and $7 \mathrm{~m})$ where there were fewer males (Kleindorfer et al. 2016). Wild avian vampire fly adults collected from Santa Cruz Island also have sex-specific microbiomes, which suggests the sexes may differ in diet and therefore foraging behaviour, perhaps due to different nutritional needs between sexes (Jose et al. 2021). Despite increasing knowledge on the avian vampire fly and its effects on hosts, we know little about where adult flies feed or mate. Mating behaviour has only been studied in a laboratory setting and has yet to be fully understood in the wild (Causton and Lahuatte pers. observation). In the laboratory, flies mate after being fed an enriched papaya diet and as well as a range of native and introduced plant species that have been offered to them, including the invasive blackberry (Causton and Lahuatte, pers. observation). As such, the agricultural zones of the inhabited islands may be an important area for avian vampire fly feeding because of the abundance of fruiting trees.

As the avian vampire fly is the greatest threat to the survival of all Galápagos land birds, it has been targeted for management and control (Causton et al. 2013). Therefore, it is critical to understand the various drivers of adult abundance and distribution. Host species nesting abundance may drive local avian vampire fly abundances, as adults may be attracted to nests for oviposition, and emerge from nests following development and pupation (Fessl et al. 2018). Although both larval and adult avian vampire fly populations occur ubiquitously across habitats (Causton et al. 2019; Dudaniec et al. 2007; Kleindorfer and Dudaniec 2016), intensity does differ across years and when accounting for host species (Kleindorfer and Dudaniec 2016).

It has been suggested that adult avian vampire fly populations may persist in highland refugia outside the host breeding season, where they can access agricultural crops 
and experience higher rainfall, and then disperse to lower, drier elevations once the host breeding season commences (Causton et al. 2013; Kleindorfer and Dudaniec 2016; Wiedenfeld et al. 2007). On Santa Cruz Island, catch rates of males decreased significantly across the non-breeding season in line with a shorter lifespan, while catch rates in females remained comparatively stable across the year (Causton et al. 2019). High rainfall was also shown to suppress daily catch rates of both male and female adult flies, likely due to decreased flight activity (Causton et al. 2019). Seasonal movements, key habitats, catch rates, and sex differences in habitat use in male and female avian vampire flies across islands are currently poorly understood. Due to the fly's geographically widespread occurrence, identifying key sites and times of peak reproductive and dispersal activity within a Darwin's finch breeding season is of special interest for the development of targeted control techniques, such as for mass release of biological control agents or sterile males.

In this study, we are interested in whether male and female avian vampire flies have different temporal or spatial distribution patterns that could be associated with different resource types (i.e. food resource $=$ fruit from agricultural zone vs. reproductive resource $=$ host nests) across two habitat types: humid, dense highlands, and dry lowlands. We quantify the number of male and female avian vampire flies captured in traps on Floreana Island, Galápagos, during the Darwin's finch breeding season in 2020 and examine patterns of avian vampire fly abundance in relation to (a) date of trapping, (b) distance to the agricultural zone, and (c) the nesting density of Darwin's finches within the highland and lowland study areas. We predict (a) female-biased sex ratio at the onset of breeding due to sex differences in minimum longevity and catch rates documented on Santa Cruz (Causton et al. 2019), (b) increased avian vampire fly abundance closer to the agricultural zone at the start of the breeding season, (c) increased avian vampire fly abundance, particularly female abundance as host nesting density increases, and (d) increased male abundance closer to the agricultural zone near higher densities of fruiting trees.

\section{Materials and methods}

\section{Study site and species}

We collected adult avian vampire flies from traps on Floreana Island, Galápagos Archipelago, between January 19th and March 6th, 2020, during the Darwin's finch breeding season. Trapping occurred in both the highlands and lowlands (Fig. 1). The highland site receives between 600 and $2300 \mathrm{~mm}$ of rain per year (Ben-Yosef et al. 2017; Charles Darwin Researcher Solanda Rea at Bella Vista; Galapagos
Conservancy 2021). The highland site is a humid Scalesia forest at an elevation of 300-400 m asl located at the base of Cerro Pajas volcano $\left(01^{\circ} 17^{\prime} \mathrm{S}, 090^{\circ} 27^{\prime} \mathrm{W}\right)$, and is adjacent to the agricultural zone $\left(01^{\circ} 18^{\prime} \mathrm{S}, 090^{\circ} 26^{\prime} \mathrm{W}\right)$. The lowland site $\left(01^{\circ} 16^{\prime} \mathrm{S}, 90^{\circ} 29^{\prime} \mathrm{W}\right)$ receives between 100 and $700 \mathrm{~mm}$ of rain per year (Charles Darwin Foundation Researcher Heinke Jäger at Puerto Ayora). The lowland is dominated by Palo Santo (Bursera graveolens) and Acacia (Parkinsonia aculeata and Scutia spicata) (Dvorak et al. 2017) with elevation of $0-150 \mathrm{~m}$ asl and is adjacent to the town of Puerto Velasco Ibarra (Fig. 1). On Floreana Island, human food production for the population ( 110 people) occurs in the highland agricultural zone with only scattered fruiting trees near homes of individual families in the lowlands. Daily highland rainfall data were collected via satellite from CPC Global Unified Precipitation Data provided by NOAA/OAR/ ESRL PSD, Boulder, CO, USA, downloaded from the Galápagos Vital Signs website (Galápagos Conservancy 2021).

The avian vampire fly is a myiasis-causing parasite whose free-living semi-hematophagous larvae feed on the developing nestlings of altricial birds (Dudaniec and Kleindorfer 2006; Fessl and Tebbich 2002). Avian vampire fly eggs are laid inside the host nests (O'Connor et al. 2010a) and once hatched, 1st instar larvae move to the nares and ear canals of newly hatched nestlings to feed on blood and tissue (Fessl et al. 2006). Second and third instar larvae generally reside in the base of the nest during the day, feeding internally (in nares) and externally on the nestlings at night (Fessl et al. 2006; O'Connor et al. 2010a). After 4-10 days of feeding, larvae pupate in a frothy cocoon in the base of the nest and emerge as adults after 7-18 days (Kleindorfer et al. 2014; Lahuatte et al. 2016). Adult flies feed on decaying vegetable matter including fruits and flowers (Fessl et al. 2018; Skidmore 1985), and can be attracted to baited traps using fruit juice lures (Lincango and Causton 2009).

\section{Avian vampire fly trapping}

Adult vampire flies were collected using baited McPhail traps hung in trees (Causton et al. 2019; Lincango and Causton 2009). Traps were baited with $150 \mathrm{~mL}$ of liquid lure composed of $600-\mathrm{g}$ ripe Hawaiian papaya, $75-\mathrm{g}$ sugar, and $4 \mathrm{~L}$ of water, blended and fermented in the sun 3 days prior to use. Trapping occurred in the highland and lowland site. At each site, traps were placed within four study plots, each containing 12 traps separated by $50 \mathrm{~m}$ in a three by four trap lattice (Fig. 1). In addition, four traps were placed in two more study plots along a single transect each separated by $50 \mathrm{~m}(N=32$ traps per site, total $N=62$ traps; Fig. 1). Traps were placed alternatively at 4 and $7 \mathrm{~m}$ high to capture potential sex ratio differences of flight height found previously by Kleindorfer et al. (2016). Bait lure was replaced and all specimens collected every 


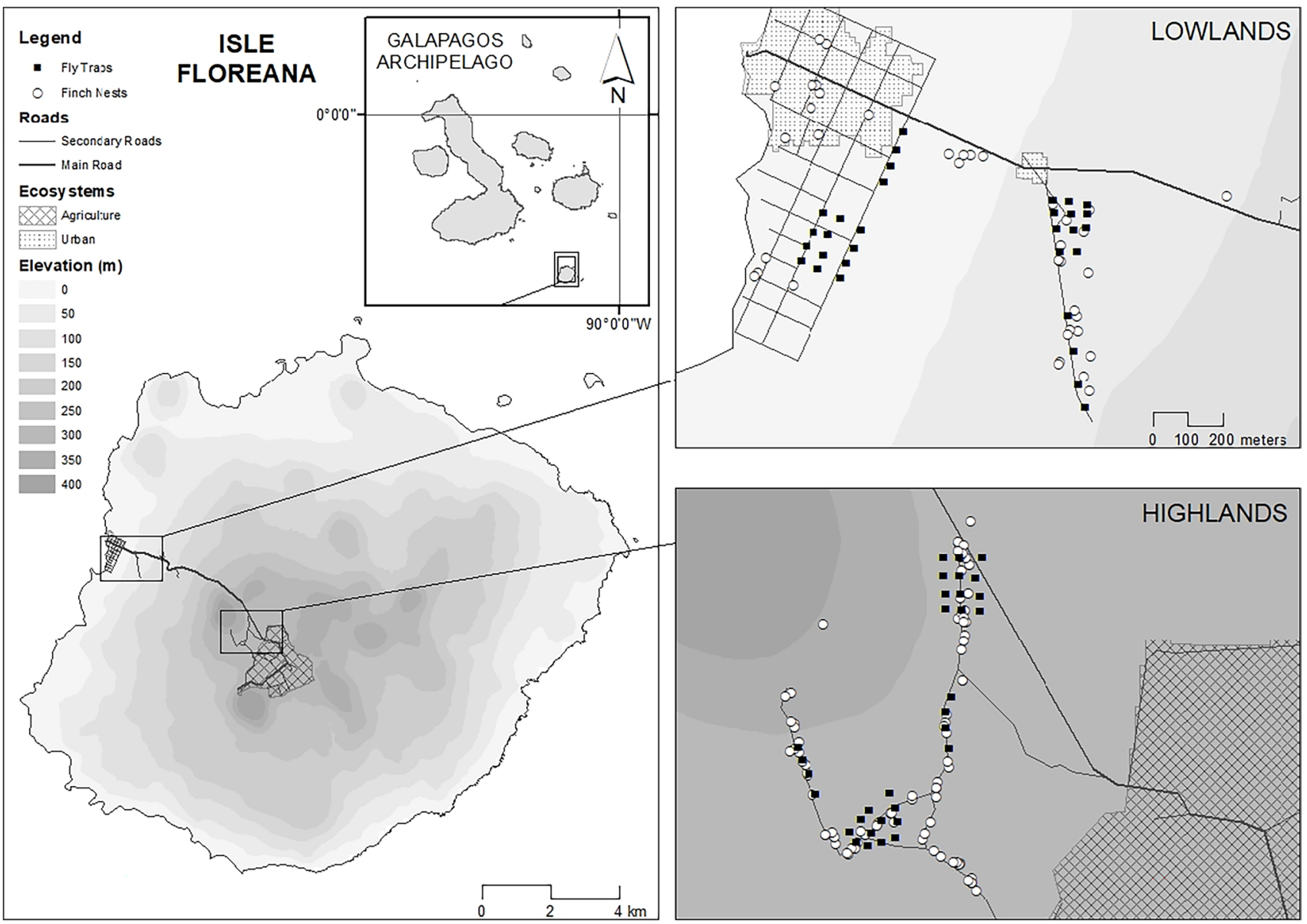

Fig. 1 Map of Floreana Island, Galápagos Archipelago. McPhail trap locations are marked with black squares, location of Darwin's finch nests monitored across the 2020 breeding season (small tree finch, medium tree finch, small ground finch and cactus finch) are marked with white dots

5 days. This was repeated nine times from January 19 th to March 5th for a total of 563 trapping events. Collected flies were stored in $70 \%$ ethanol, identified, and sexed under a stereomicroscope following morphology described in Kleindorfer et al. (2016).

GPS coordinates were collected for each trap as they were deployed. Distance of each trap to the agricultural zone boundary was calculated using coordinate data. The host nesting density, i.e. the number of active Darwin's finch nests per $200 \mathrm{~m} \times 100 \mathrm{~m}$ study plot, was collected from our long-term nest monitoring protocol (see Kleindorfer et al. 2014), which occurred concurrently with trapping. Search effort for active nests within study plots was equal across highland and lowland sites. The host species monitored were the small ground finch (Geospiza fuliginosa), cactus finch (Geospiza scandens), small tree finch (Camarhynchus parvulus), medium tree finch (C. pauper), and the hybrid tree finch $(C$. parvulus $\times C$. pauper as well as introgressed individuals). Each monitored host nest that was with eggs (incubation phase) or nestlings (feeding phase) within each study plot $(100 \mathrm{~m} \times 200 \mathrm{~m})$ during each trapping period (5 days) was counted as an active nest, giving a nesting density of Darwin's finch nests per plot for each trapping event.

\section{Mapping}

Map figures were prepared using ArcMap 10.8.1 (ESRI 2011), with UTM 15S projection. Primary data obtained via ESRI Web Map included Ecosistemas Galápagos 2016, and Vías (roads) layers (ESRI 2017). The shoreline was obtained from NOAA Shoreline World Vector Shoreline (NOAA 2016; Wessel and Smith 1996) and the Digital Elevation Model (Souris 2018) was used to create elevation vectors at 50-m intervals for display purposes.

\section{Statistical analysis}

All models were fitted in R version 4.0.0 (R Core Development Team 2020) using the packages 'Ime4' (Bates et al. 2015), 'car' (Fox and Weisberg 2011), and 'effects' (Fox 2003). Results are presented as estimate \pm standard error, unless otherwise stated. Total number of avian vampire 
flies $(N=417)$ across habitats (lowlands: $N=12$; highlands: $N=405)$ was analysed using a generalised linear mixed model (GLMM) with negative binomial distribution to account for the non-normal distribution and over-dispersion of the count data. To incorporate the dependency among observations of the same trap, we used 'trap ID' as random intercept. To test for the effects of rainfall in highland avian vampire fly abundance, average daily rainfall was calculated per trapping event (5 days) for both sites. However, due to the strong correlation between average daily rainfall and Julian date (Pearson's correlation test: rho $=-0.71$ ), rainfall was excluded from further analysis; patterns of rainfall for highlands are instead described in the results. The number of highland avian vampire flies caught in traps was analysed using negative binomial GLMM in relation to Julian date, distance to agricultural zone and host nest, the interaction term Julian date $\times$ distance to agricultural zone, with trap ID as a random intercept $(N=417)$ and a log link function. Corresponding analysis for male $(N=199)$ and female $(N=205)$ highland abundance in relation to Julian date, distance to agricultural zone, host nesting density, and number of the opposite sex caught in the same trap was analysed using GLMMs with negative binomial distribution, log link function, and trap ID as a random intercept. The proportion of male avian vampire flies, representing the sex ratio, was analysed separately for the highlands in relation to Julian date, distance to agricultural zone, and host nesting density using a GLM with the command bind ('cbind') function specifically designed to fit ratio data within the binomial family. The number of male avian vampire flies was the binomial denominator, quasibinomial (correct for overdispersion) distribution, and a logit link function. All quantitative variables were scaled $($ mean $=0$ and standard deviation $=1)$ to bring variables into comparable scales and allow interpretation

Table 1 (a) Highland and lowland avian vampire flies (Philornis downsi) from McPhail traps collected during the Darwin's finch breeding season. Generalized linear mixed model with negative binomial distribution for total number of adult avian vampire flies caught in relation to habitat, Julian date, and host nesting density. Trap ID was used as a random factor (variance $=0.145 \pm 0.38$ ). (b) General- of the magnitude of all main effects (Grueber et al. 2011). Here, we report model effect sizes as estimate \pm SE (summary function in 'Ime4'; Bates et al. 2015); $\chi^{2}$ and $p$-values from the ANOVA Table of Deviance using Type III $\chi^{2}$ tests (ANOVA function in the package 'car'; Fox and Weisberg 2011).

\section{Results}

The number of avian vampire flies was significantly higher in the highlands compared to the lowlands (GLMM, $3.49 \pm 0.33, p<0.001$, Table 1; Fig. 2; Supplementary Fig. 1). Catch rates increased across the breeding season $(0.57 \pm 0.07, p<0.001$, Table 1$)$. There was no effect of host nesting density on the number of flies caught $(0.03 \pm 0.07$, $p=0.715$, Table 1) and distance to agricultural zone was not included in the most parsimonious model. Trap ID accounted for $0.145 \pm 0.38$ of the variance in fly abundance. We caught a total of 12 avian vampire flies in the lowlands $(0.003$ males and 0.005 females per trap per day) and 405 in the highlands ( 0.135 males and 0.140 females per trap per day). At the onset of trapping (January 19th), which occurred before the onset of Darwin's finch egg laying and nesting (approximately January 25th in highlands, January 31 st in lowlands), we caught 13 males and 15 females from 59 traps in January in the highlands and no males or females from 62 traps in the lowlands. Average daily rainfall decreased across the study period $(t=-17.037, \mathrm{df}=282$, rho $=-0.71, p<0.001)$. During the first trapping period in the highlands (January 20th-25th), there was $31.9 \mathrm{~mm}$ of rain per day. At the end of the study period (February 29th-March 5th), rainfall was $2.0 \mathrm{~mm}$ per day.

ized linear model with quasibinomial distribution for avian vampire fly sex ratio in the highlands in relation to Julian date, distance to agricultural zone, and host nesting density. Sex ratio calculated as the proportion of male flies in relation to female flies. Avian vampire flies collected from McPhail traps on Floreana Island during the 2020 Darwin's finch breeding season

\begin{tabular}{|c|c|c|c|c|c|c|}
\hline (a) Total number of Philornis downsi $(N=417)$ & Estimate & SE & $z$-value & $\operatorname{LR} \chi^{2}$ & df & $P$-value \\
\hline Intercept & -3.384 & 0.31 & -10.938 & & & $<0.001$ \\
\hline Habitat & 3.492 & 0.33 & 10.582 & 111.99 & 1 & $<0.001$ \\
\hline Julian date & 0.586 & 0.07 & 8.122 & 65.96 & 1 & $<0.001$ \\
\hline Host nesting density & 0.027 & 0.07 & 0.365 & 0.13 & 1 & 0.089 \\
\hline (b) Highland $P$. downsi sex ratio $(N=405)$ & Estimate & SE & $t$-value & $\operatorname{LR} \chi^{2}$ & df & $P$-value \\
\hline Intercept & -0.130 & 0.12 & -1.077 & & & 0.283 \\
\hline Julian date & 0.207 & 0.11 & 1.810 & 3.318 & 1 & 0.072 \\
\hline Distance to agricultural zone & -0.516 & 0.11 & -4.731 & 23.686 & 1 & $<0.001$ \\
\hline Host nesting density & -0.051 & 0.12 & -0.415 & 0.173 & 1 & 0.678 \\
\hline
\end{tabular}

Dispersion parameter for negative binomial model (a) taken to be 1.981 for quasibinomial model (b) taken to be 0.938 

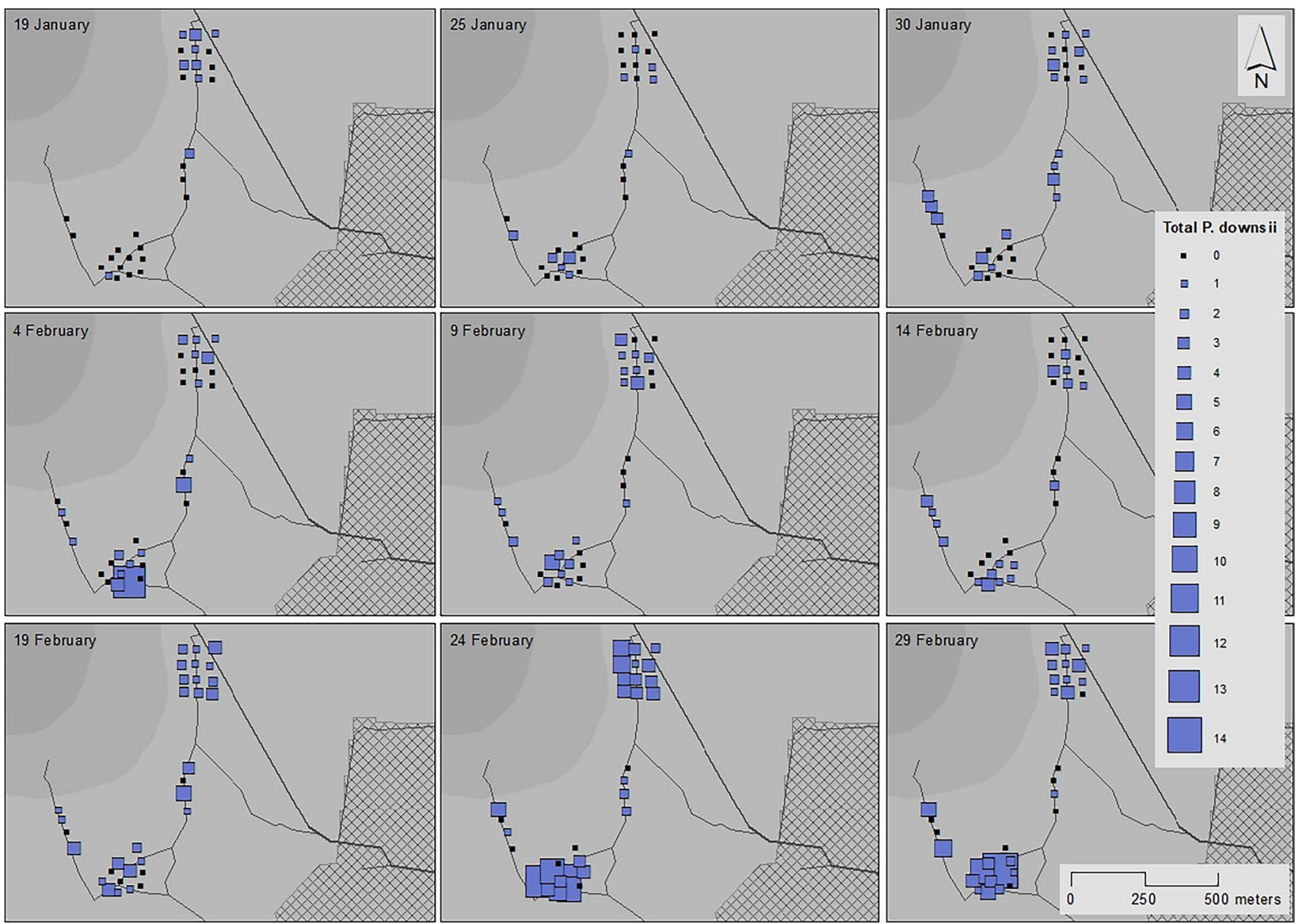

Fig. 2 Avian vampire fly abundance per trapping event (top left of each frame indicates date of trap deployment, trapping events last 5 days) in the highlands of Floreana Island during the 2020 Darwin's Finch breeding season (January 19th to March 5th)

\section{Lowlands}

Flies were not collected in the lowlands until the fourth replicate of trapping (February 5th-February 10th; Supplementary Fig. 1), despite equal trapping effort across the season and across habitats. On the contrary, in the highlands, flies were collected in the first replicate of trapping (January 20th-January 25th; Fig. 2). Due to the small sample size of flies collected in the lowlands $(N=12)$ and low statistical power, we are unable to analyse the effects of host nesting density on adult avian vampire fly abundance or change in sex ratio across the season in the lowlands.

\section{Highlands}

Highland avian vampire fly abundance $(N=405)$ increased across the breeding season (GLMM, $0.57 \pm 0.07, p<0.001$, Table 2, Fig. 2). There was no effect of distance to the agricultural zone $(0.09 \pm 0.01, p=0.370$, Table 2$)$ or host nesting density $(0.04 \pm 0.08, p=0.607$, Table 2$)$ on the overall abundance in the highlands. There was also no interaction effect between trapping date and distance to the agricultural zone $(-0.08 \pm 0.07, p=0.273)$. Trap ID accounted for $0.16 \pm 0.40$ of the variance in highland abundance. The sex ratio did not change significantly across the breeding season (GLM, $0.21 \pm 0.12, p=0.072$, Table 1$)$. There was no effect of host nesting density $(N=16$ total active nests in highland study plots across breeding season, Fig. 3) on sex ratio when accounting for date of capture $(-0.05 \pm 0.12$, $p=0.679$, Table $1 ;$ Fig. 3 ). The sex ratio was highly skewed towards males closer to the agricultural zone $(-0.51 \pm 0.11$, $p<0.001$, Table 1) and skewed towards females further from the agricultural zone.

Examining abundance patterns in each sex in the highlands separately, male avian vampire fly abundance $(N=199)$ increased across the breeding season (GLMM, $0.54 \pm 0.10, p<0.001$, Table 2), and increased closer to the agricultural zone $(-0.27 \pm 0.10, p=0.008,2)$, with no effect of host nesting density $(0.04 \pm 0.10, p=0.653$, Table 2). There was a positive association between the number of male flies and female flies collected in the same trap $(0.37 \pm 0.07, p<0.001$, Table 2$)$, as the number of 
Table 2 Highland avian vampire flies (Philornis downsi) from McPhail traps collected in 2020 during the Darwin's finch breeding season from Jan to Mar. Generalised linear mixed model for (a) total number of adult avian vampire flies in relation to Julian date, distance to agricultural zone, elevation, and host nesting density (random factor trap ID variance $=0.16 \pm 0.40$ ); (b) number of male avian vampire flies in relation to Julian date, distance to agricultural zone, host nesting density, and number of females (trap ID variance $=0.06 \pm 0.25$ ); (c) number of female avian vampire flies in relation to Julian date, distance to agricultural zone, host nesting density, and number of males (trap ID variance $=3.4 \times 10^{-9} \pm 5.8 \times 10^{-5}$ ). $\mathrm{N}$ is the raw number of flies caught

\begin{tabular}{|c|c|c|c|c|c|c|}
\hline a) Total number of Philornis downsi $(N=405)$ & Estimate & SE & $z$-value & $\operatorname{LR} \chi^{2}$ & $\mathrm{df}$ & $P$-value \\
\hline Intercept & 0.106 & 0.11 & 1.005 & & & 0.315 \\
\hline Julian date & 0.562 & 0.07 & 7.627 & 58.167 & 1 & $<0.001$ \\
\hline Distance to agricultural zone & 0.065 & 0.10 & 0.648 & 0.420 & 1 & 0.517 \\
\hline Host nesting density & 0.042 & 0.08 & 0.076 & 0.300 & 1 & 0.584 \\
\hline Julian date $\times$ Distance to agricultural zone & -0.081 & 0.07 & -1.096 & 1.201 & 1 & 0.273 \\
\hline b) Male Philornis downsi $(N=199)$ & Estimate & SE & $z$-value & $\operatorname{LR} \chi^{2}$ & $\mathrm{df}$ & $P$-value \\
\hline Intercept & -0.735 & 0.12 & -6.260 & & & $<0.001$ \\
\hline Julian date & 0.544 & 0.10 & 5.420 & 29.373 & 1 & $<0.001$ \\
\hline Distance to agricultural zone & -0.267 & 0.10 & -2.645 & 6.994 & 1 & 0.008 \\
\hline Host nesting density & 0.045 & 0.10 & 0.449 & 0.202 & 1 & 0.653 \\
\hline Number of females & 0.373 & 0.07 & 5.238 & 27.440 & 1 & $<0.001$ \\
\hline c) Female Philornis downsi $(N=205)$ & Estimate & SE & $z$-value & $\operatorname{LR} \chi^{2}$ & df & $P$-value \\
\hline Intercept & -0.548 & 0.09 & -6.244 & & & $<0.001$ \\
\hline Julian date & 0.283 & 0.09 & 3.269 & 10.687 & 1 & $<0.001$ \\
\hline Distance to agricultural zone & 0.380 & 0.08 & 4.676 & 21.862 & 1 & $<0.001$ \\
\hline Host nesting density & 0.039 & 0.08 & 0.464 & 0.215 & 1 & 0.643 \\
\hline Number of males & 0.372 & 0.06 & 6.582 & 43.329 & 1 & $<0.001$ \\
\hline
\end{tabular}

Dispersion parameter for negative binomial model (a) taken to be 1.925 ; (b) taken to be 2.455 ; (c) taken to be 5.966

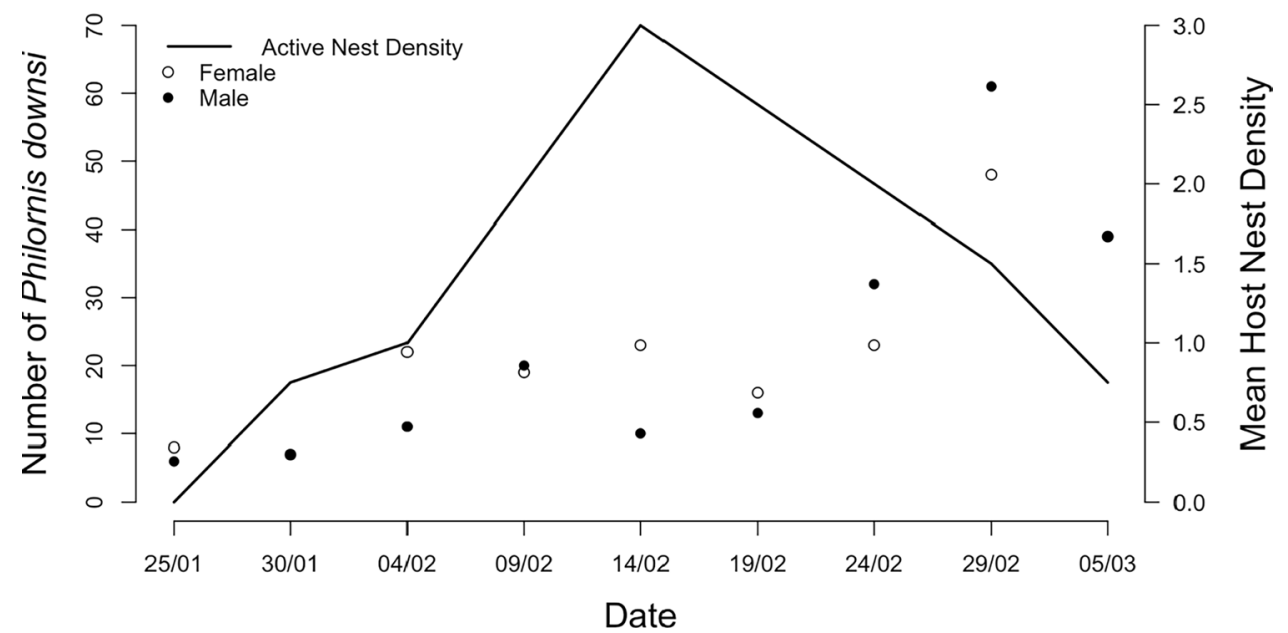

Fig. 3 Highland number of male and female avian vampire flies (Philornis downsi) across date of collection (trapping replicate duration 5 days) with mean host nesting density per study plot $(200 \mathrm{~m} \times 100 \mathrm{~m})$. Open circles represent the number of female avian vampire flies caught in the highlands during a trapping event, closed

female flies increased, so did the number of male flies. Trap ID accounted for $0.06 \pm 0.25$ of the variance in male fly abundance. Female avian vampire fly abundance $(N=205)$ increased across the breeding season (GLMM, $0.28 \pm 0.09, p<0.001$, Table 2), decreased closer to circles represent the number of male avian vampire flies caught across the same time period. Avian vampire flies collected from McPhail traps in the highlands of Floreana Island in 2020 during the Darwin's finch breeding season (January 19th to March 5th)

the agricultural zone $(0.38 \pm 0.08, p<0.001$, Table 2$)$, and did not increase in relation to host nesting density $(0.04 \pm 0.08, p=0.643$, Table 2 ; Fig. 3$)$. Trap ID only accounted for $3.4 \times 10^{-9} \pm 5.8 \times 10^{-5}$ of the variance in female abundance. 


\section{Discussion}

Understanding sex-specific range use, key resources, and habitat use by populations is critical for developing effective control techniques for invasive species. We found significant differences in temporal patterns of abundance of the invasive avian vampire fly across the Darwin's finch breeding season and two habitat types on Floreana Island. The number of flies caught in traps increased significantly across the breeding season (January-March), which might be due to increasing numbers of adult flies emerging from host nests towards the end of the host breeding season. The prevalence of $P$. downsi in monitored nests with nestlings was $100 \%$; however, if the nests failed during incubation, no avian vampire fly larvae were found. Contrary to our prediction, there was no effect of host nesting density on overall abundance or sex-specific abundance. Our data suggest that avian vampire flies may use the highland Scalesia and nearby agricultural zone as a refugium during the non-breeding season. Adult flies were collected in the highlands during the first trapping event but were not collected in the lowlands until 20 days into trapping. Avian vampire flies may have dispersed from the humid highlands to the arid lowlands as host breeding increased, as there is evidence that adult flies are capable of dispersing large distances (Fessl et al. 2018). We did not find support for our predictions of a female-biased sex-ratio or increased abundance near the agricultural zone at the onset of the breeding season. This contrasts with previous research that found males have a shorter lifespan and are unlikely to survive to the next year's breeding season, resulting in a female-biased sex ratio (Causton et al. 2019). Although the sex ratio remained stable across habitats (highlands vs lowlands) and time, we caught more male avian vampire flies closer to the agricultural zone, with females showing the opposite pattern. Our results highlight the importance of the highland habitat, on Floreana Island, as a key location to plan control measures for the avian vampire fly.

The sex differences in catch numbers close to the agricultural zone raise questions about the mating behaviour of the avian vampire fly. It is possible, though untested, that males near the agricultural zone may be guarding food resources or lekking near fruits to attract females. In many species that display resource-based mating, males defend oviposition sites, with both mating and oviposition occurring at the guarded site (Preston-Mafham 2001; Warburg and Yuval 1997; Wilkinson and Johns 2005). This may not be a preferred option for male avian vampire flies, due to the presence of the incubating or brooding female at the nest (Kleindorfer et al. in review). There is video evidence that avian vampire flies wait outside the host nest, only entering once the nest is unattended, and leaving once the female returns (Lincango et al. 2015; O'Connor et al. 2010a). There may be a risk of predation by the insectivorous bird if a fly enters or mates near an occupied nest, making the host nest a less attractive 'mate attraction' resource, especially when considering that the length of mating reported under laboratory conditions is often between 5 and 7 min (Causton and Lahuatte et al., pers. comms.). Sex differences in dispersal or climatic tolerance (Enriquez and Colinet 2017; Lyons et al. 2014; Miller and Inouye 2013) are other explanations for the possible differences in spatial patterns we observed. The proximity to the agricultural zone stands out as a key element that warrants further study and points to possible differences in nutritional needs between the sexes or mating behaviour. A key factor known to drive sex-specific ranges is male harassment, which may operate in conjunction with or independently of the mating system (Stanley et al. 2018; Stone 1995). Male harassment, and its associated costs to females, has previously been suggested as one possible explanation for sex-specific micro-habitat use in the avian vampire fly (Kleindorfer et al. 2016), though it is still untested. Due to the limitations of this study, we are unable to determine the cause of the sex-specific distribution in avian vampire fly on Floreana Island during 2020. Future research could test ideas to disentangle the potential role of mating system and foraging ecology in avian vampire flies in relation to proximity to fruiting trees in the agricultural zone.

Although we did not find a correlation between host nesting density and number of avian vampire flies, there may be a time lag between nest termination and fly emergence, and therefore an increase in fly abundance. Due to the restricted sampling period of this study, we do not know how the abundance of the avian vampire fly changes after host breeding has finished on Floreana. On Santa Cruz, female catch rates remained approximately stable across the non-breeding season, with male catch rates decreasing between breeding seasons (Causton et al. 2019). It is possible that the fly population decreases slowly after the breeding season as adult flies die off. This is in contrast to the rapid drop-off in nesting density seen in this study, which may be why we did not find a relationship between fly abundance and host density; however, this remains to be tested. Other host-parasite systems display a parallel pattern of density in host and parasite populations (Byers et al. 2008; Oorebeek and Kleindorfer 2008; Young et al. 2015); however, this pattern is not universal (Cardon et al. 2011). Extending the trapping duration outside of the host breeding season can further explore the sex-specific population dynamics on Floreana Island in relation to host nesting density.

The marked habitat differences in number of flies caught between highlands $(N=405)$ and lowlands $(N=12)$ could 
be explained by rainfall, host density, or number of fruiting trees, whereby our patterns stand in marked contrast to those found on Santa Cruz Island (Causton et al. 2019). On Santa Cruz Island, catch rates of avian vampire fly adults, in particular female flies, was higher in lowland sites compared to highland sites (Causton et al. 2019). Differences in catch rates between the sexes in these two studies- 0.08 females vs 0.08 males per trap per day in this study compared to 0.25 females vs 0.08 males per trap per day in Causton et al. (2019) — are likely due to the differences in sampling duration (6 weeks versus 1 year). It is also notable that the Santa Cruz lowland sites were sampled near a dense urban area with higher human population and potential access to fruiting trees, fresh water, and human food (INEC 2015). Causton et al. (2019) trapped adults across the entire year and found lower catch rates for male avian vampire flies during the host non-breeding season. In contrast to Causton et al. (2019), we did not catch fewer males at the start of the host breeding season. The number of birds is generally lower in the lowlands than in the highlands on both Santa Cruz and Floreana Islands (Dvorak et al. 2012; Dvorak et al. 2017). In terms of nesting, across the same time period, monitoring effort, and area, we encountered five lowland nests with eggs and 16 highland nests with eggs (Kleindorfer et al. unpublished). While the summary data suggest that host nesting density could explain the different trapping success in lowlands versus highlands, the host nesting density did not predict the number of adult flies caught in highland traps, and so we reject this explanation. We suggest that rainfall, human population, and fruiting trees may be more important factors for avian vampire fly abundance.

Although our results are based on one season of data, the clear patterns combined with conservation urgency call for future research and targeted intervention. For example, the Sterile Insect Technique (Hendrichs et al. 2002), whereby large numbers of sterile insects that produce no offspring are released, could be targeted to high male density areas. Utilising mating or attractant pheromones to disrupt mating (Carde and Minks 1995) can be deployed where mating most commonly occurs. Future research should extend trapping into the non-breeding season and within the agricultural zone at particular fruiting trees to determine patterns of migration across habitat types (Midgarden et al. 2014). Sex-specific population control could be effective in managing and eradicating invasive populations, especially in populations that display sex segregation (Papathanos et al. 2014). If the avian vampire fly is restricted to the highlands and agricultural zone during the non-breeding season, with males primarily distributed in the agricultural zone, this could be a critical area for male population suppression (Hendrichs et al. 2005). Male annihilation techniques, such as those used to decrease fruit fly populations, could be used during the non-breeding season to decrease male density, which can be used alone or in conjunction with sterile insect release (Vargas et al. 2014). With promising developments on survival rates for reared avian vampire fly larvae in a laboratory setting (Lahuatte et al. 2016), the potential for sterile insect breeding and release is increasing, although more research is needed.

Invasive parasites often pose challenges to biodiversity, but they also represent a chance to learn about novel hostparasite systems under new evolutionary selection regimes (Allendorf and Lundquist 2003; Sakai et al. 2001). In an emerging host-parasite system on Floreana that was likely established after 1960 (Kleindorfer and Sulloway 2016), and has been studied since 2004 (Kleindorfer et al. 2014), we find differences between habitats in numbers of adult flies and sex ratio in relation to proximity to the agricultural zone and across the breeding season. In neither sex did host nesting density predict number of flies caught, but we caught more males close to the agricultural zone at the onset of the breeding season. Intriguingly, the patterns we found are markedly different from those on Santa Cruz Island (Causton et al. 2019), where the number of flies caught was higher in the lowlands than in the highlands and a female-biased sex ratio at the onset of the host breeding season occurred. If the avian vampire fly populations are inhabiting different areas on different islands, this could pose additional challenges for biological control. Future work should extend trapping into the non-breeding season and assess long-term abundance changes in host and parasite abundances across years. Understanding of the movements and populations of both sexes of the avian vampire fly, such as the findings of this study, can inform island-specific targeted control, particularly relevant to control techniques that manipulate breeding behaviour such as the Sterile Insect Technique and pheromonebased mating disruption. This information, as well as the possible occurrence of lag effects of parasite abundance, would further inform the optimal timing and distribution of deploying control efforts. Further research into the spatial and temporal behaviour and ecology of the avian vampire fly in relation to island is critical to untangle the various drivers of adult populations in its invasive range.

Supplementary Information The online version contains supplementary material available at https://doi.org/10.1007/s00436-021-07350-1.

Acknowledgements We thank the Galápagos National Park and the Charles Darwin Foundation for permission to conduct research and for their logistical support. We thank Charles Darwin Foundation Researchers Heinke Jäger and Solanda Rea for providing rainfall data from Santa Cruz. We thank the community of Floreana Island for their continued support. We thank David Arango Roldán, Çağlar Akçay, Jefferson García Loor, Mario Gallego-Abenza, Alena Hohl, Leon Hohl, Andrew Katsis, Petra Pesak, and Verena Puehringer-Sturmayr for field 
work assistance. This publication is contribution number 2411 of the Charles Darwin Foundation of the Galápagos Islands.

Author contribution Lauren K. Common and Sonia Kleindorfer designed the study and collected the data. Shane Sumasgutner created the maps and figures. Lauren K. Common analysed the data and wrote the manuscript. All authors discussed the results, edited the manuscript, and provided critical feedback.

Funding Open access funding provided by University of Vienna. Funding for this study was provided by the Australian Research Council, Macquarie University, and the University of Vienna.

Data availability Data reported in this study will be uploaded to Dryad Digital Repository upon acceptance.

\section{Declarations}

Permits Permission to conduct this study was given by the Galápagos National Park and Charles Darwin Research Center, permit no. PC-0220: Invasivos e invasivos: estableciendo la línea base para evaluar la iniciativa de control de roedores en Floreana sobre la densidad y comportamiento de anidación de pinzones de Darwin y el parasitismo por Philornis downsi, and Flinders University, permit no. E480/19.

Conflict of interest The authors declare no competing interests.

Open Access This article is licensed under a Creative Commons Attribution 4.0 International License, which permits use, sharing, adaptation, distribution and reproduction in any medium or format, as long as you give appropriate credit to the original author(s) and the source, provide a link to the Creative Commons licence, and indicate if changes were made. The images or other third party material in this article are included in the article's Creative Commons licence, unless indicated otherwise in a credit line to the material. If material is not included in the article's Creative Commons licence and your intended use is not permitted by statutory regulation or exceeds the permitted use, you will need to obtain permission directly from the copyright holder. To view a copy of this licence, visit http://creativecommons.org/licenses/by/4.0/.

\section{References}

Allendorf FW, Lundquist LL (2003) Introduction: Population biology, evolution, and control of invasive species. Conserv Biol 17(1):24 30. https://doi.org/10.1046/j.1523-1739.2003.02365.x

Bates D, Mächler M, Bolker B, Walker S (2015) Fitting linear mixedeffects models using lme4. J Stat Softw 1(1):2015. https://doi.org/ 10.18637/jss.v067.i01

Beirinckx K, Van Gossum H, J. Lajeunesse M, R. Forbes M, (2006) Sex biases in dispersal and philopatry: insights from a metaanalysis based on capture-mark-recapture studies of damselflies. Oikos 113(3):539-547. https://doi.org/10.1111/j.2006.0030-1299. 14391.x

Ben-Yosef M et al (2017) Host-specific associations affect the microbiome of Philornis downsi, an introduced parasite to the Galápagos Islands. Mol Ecol 26(18):4644-4656. https://doi.org/10. 1111/mec.14219

Bierzychudek P, Eckhart V (1988) Spatial segregation of the sexes of dioecious plants. Am Nat 132(1):34-43. https://doi.org/10.1086/ 284836
Byers JE, Blakeslee AMH, Linder E, Cooper AB, Maguire TJ (2008) Controls of spatial variation in the prevalence of trematode parasites infecting a marine snail. Ecology 89(2):439-451. https://doi. org/10.1890/06-1036.1

Carde RT, Minks AK (1995) Control of moth pests by mating disruption: successes and constraints. Annu Rev Entomol 40(1):559-585

Cardon M, Loot G, Grenouillet G, Blanchet S (2011) Host characteristics and environmental factors differentially drive the burden and pathogenicity of an ectoparasite: a multilevel causal analysis. J Anim Ecol 80(3):657-667. https://doi.org/10.1111/j.1365-2656. 2011.01804.x

Causton C, Cunninghame F, Tapia W (2013) Management of the avian parasite Philornis downsi in the Galapagos Islands: a collaborative and strategic action plan Galapagos Report 2011-2012. vol 2012. GNPS, GCREG, CDF and GC, Puerto Ayora, Galapagos, Ecuador, p 167-173

Causton CE et al (2019) Population dynamics of an invasive bird parasite, Philornis downsi (Diptera: Muscidae), in the Galapagos Islands. PLoS ONE 14(10):e0224125. https://doi.org/10.1371/ journal.pone. 0224125

Causton CE, Peck SB, Sinclair BJ, Roque-Albelo L, Hodgson CJ, Landry B (2006) Alien insects: threats and implications for conservation of Galápagos Islands. Ann Entomol Soc Am 99(1):121-143. https://doi.org/10.1603/0013-8746(2006)099[0121:AITAIF]2.0. $\mathrm{CO} ; 2$

Choe JC, Crespi BJ (1997) The evolution of mating systems in insects and arachnids. Cambridge University Press Cambridge

Conservancy G (2021) Galapagos Vital Signs: a satellite-based environmental monitoring system for the Galapagos Archipelago. https://galapagosvitalsigns.org Accessed 12 Jan 2021

Dodson GN (1997) Resource defense mating system in antlered flies, Phytalmia spp. (Diptera: Tephritidae). Annals of the Entomological Society of America 90(4):496-504 doi:https://doi.org/10. 1093/aesa/90.4.496

Dudaniec RY, Carey AR, Svensson EI, Hansson B, Yong CJ, Lancaster LT (2021) Latitudinal clines in sexual selection, sexual size dimorphism, and sex-specific genetic dispersal during a poleward range expansion. J Anim Ecol 00:1-5. https://doi.org/10.1111/ 1365-2656.13488

Dudaniec RY, Fessl B, Kleindorfer S (2007) Interannual and interspecific variation in intensity of the parasitic fly, Philornis downsi. Darwin's Finches Biological Conservation 139(3):325-332. https://doi.org/10.1016/j.biocon.2007.07.006

Dudaniec RY, Gardner MG, Kleindorfer S (2010) Offspring genetic structure reveals mating and nest infestation behaviour of an invasive parasitic fly (Philornis downsi) of Galápagos birds. Biol Invasions 12(3):581-592. https://doi.org/10.1007/s10530-009-9464-x

Dudaniec RY, Kleindorfer S (2006) Effects of the parasitic flies of the genus Philornis (Diptera: Muscidae) on birds. Emu - Austral Ornithology 106(1):13-20. https://doi.org/10.1071/MU04040

Dunn AM, Hatcher MJ (2015) Parasites and biological invasions: parallels, interactions, and control. Trends Parasitol 31(5):189-199. https://doi.org/10.1016/j.pt.2014.12.003

Dvorak M, Fessl B, Nemeth E, Kleindorfer S, Tebbich S (2012) Distribution and abundance of Darwin's finches and other land birds on Santa Cruz Island, Galápagos: evidence for declining populations. Oryx 46(1):78-86. https://doi.org/10.1017/S0030605311000597

Dvorak $\mathrm{M}$ et al (2017) Conservation status of landbirds on Floreana: the smallest inhabited Galápagos Island. J Field Ornithol 88(2):132-145. https://doi.org/10.1111/jofo.12197

Emlen ST, Oring LW (1977) Ecology, sexual selection, and the evolution of mating systems. Science 197(4300):215-223

Enkerlin WR et al (2017) The Moscamed Regional Programme: review of a success story of area-wide sterile insect technique application. Entomol Exp Appl 164(3):188-203. https://doi.org/10.1111/ eea. 12611 
Enriquez T, Colinet H (2017) Basal tolerance to heat and cold exposure of the spotted wing drosophila. Drosophila Suzukii Peerj 5:e3112. https://doi.org/10.7717/peerj.3112

Escobar LE, Moen R, Craft ME, VanderWaal KL (2019) Mapping parasite transmission risk from white-tailed deer to a declining moose population. Eur J Wildl Res 65(4):60. https://doi.org/10. 1007/s10344-019-1297-z

ESRI (2011) ArcGIS Desktop: Release 10. Environmental Systems Research Institute, Redlands, CA

ESRI (2017) Data Galapagos: Web Map. Environmental Systems Research Institute. https://www.arcgis.com/home/item.html?id= ff95a67b2d8149ff9ab2c1feebca8b8c. Accessed 4 Dec 2020

Fessl B, Couri MS, Tebbich S (2001) Philornis downsi Dodge \& Aitken, new to the Galapagos Islands (Diptera, Muscidae). Studia Dipterologica 8(1):317-322

Fessl B, Heimpel GE, Causton CE (2018) Invasion of an avian nest parasite, Philornis downsi, to the Galápagos Islands: colonization history, adaptations to novel ecosystems, and conservation challenges. In: Parker PG (ed) Disease Ecology: Galapagos Birds and their Parasites. Springer International Publishing, Cham, pp 213-266

Fessl B, Sinclair BJ, Kleindorfer S (2006) The life-cycle of Philornis downsi (Diptera: Muscidae) parasitizing Darwin's finches and its impacts on nestling survival. Parasitology 133(6):739-747. https://doi.org/10.1017/S0031182006001089

Fessl B, Tebbich S (2002) Philornis downsi- a recently discovered parasite on the Galápagos archipelago - a threat for Darwin's finches? Ibis 144(3):445-451. https://doi.org/10.1046/j.1474919X.2002.00076.X

Fessl B et al (2010) How to save the rarest Darwin's finch from extinction: the mangrove finch on Isabela Island. Philosophical Transactions of the Royal Society b: Biological Sciences 365(1543):1019-1030. https://doi.org/10.1098/rstb.2009.0288

Foster SE, Soluk DA (2006) Protecting more than the wetland: the importance of biased sex ratios and habitat segregation for conservation of the Hine's emerald dragonfly. Somatochlora Hineana Williamson Biological Conservation 127(2):158-166. https://doi. org/10.1016/j.biocon.2005.08.006

Fox J (2003) Effect displays in R for generalised linear models. J Stat Softw 1(15):2003. https://doi.org/10.18637/jss.v008.i15

Fox J, Weisberg S (2011) An R companion to applied regression. Sage Publications, California

González C et al (2017) Entomological characterization of malaria in northern Colombia through vector and parasite species identification, and analyses of spatial distribution and infection rates. Malar J 16(1):431. https://doi.org/10.1186/s12936-017-2076-5

Grueber CE, Nakagawa S, Laws RJ, Jamieson IG (2011) Multimodel inference in ecology and evolution: challenges and solutions. $\mathrm{J}$ Evol Biol 24(4):699-711. https://doi.org/10.1111/j.1420-9101. 2010.02210.x

Hendrichs J, Katsoyannos BI, Papaj DR, Prokopy RJ (1991) Sex differences in movement between natural feeding and mating sites and tradeoffs between food consumption, mating success and predator evasion in Mediterranean fruit flies (Diptera: Tephritidae). Oecologia 86(2):223-231. https://doi.org/10.1007/BF00317534

Hendrichs J, Robinson AS, Cayol JP, Enkerlin W (2002) Medfly areawide sterile insect technique programmes for prevention, suppression or eradication: the importance of mating behavior studies. Florida Entomologist 85(1):1-13. https://doi.org/10.1653/ 0015-4040(2002)085[0001:MASITP]2.0.CO;2

Hendrichs J, Vreysen M, Enkerlin W, Cayol J, Dyck V, Robinson A (2005) Strategic options in using sterile insects for area-wide integrated pest management. In: V.A. D, J. H, A. R (eds) Sterile Insect Technique. Springer, Dordrecht, p 841
INEC (2015) Censo de Población y Vivienda Galápagos 2015. Instituto Nacional de Estadística y Censos, Ecuador

Jose PA et al (2021) Shifting microbiomes complement life stage transitions and diet of the bird parasite Philornis downsi from the Galapagos Islands. Environ Microbiol. https://doi.org/10.1111/ 1462-2920.15435

Kleindorfer S, Custance G, Peters Katharina J, Sulloway Frank J (2019) Introduced parasite changes host phenotype, mating signal and hybridization risk: Philornis downsi effects on Darwin's finch song. Proceedings of the Royal Society b: Biological Sciences 286(1904):20190461. https://doi.org/10.1098/rspb.2019.0461

Kleindorfer S, Dudaniec RY (2016) Host-parasite ecology, behavior and genetics: a review of the introduced fly parasite Philornis downsi and its Darwin's finch hosts. BMC Zoology 1(1):1. https:// doi.org/10.1186/s40850-016-0003-9

Kleindorfer S, Peters KJ, Custance G, Dudaniec RY, O'Connor JA (2014) Changes in Philornis infestation behavior threaten Darwin's finch survival. Current Zoology 60(4):542-550. https://doi. org/10.1093/czoolo/60.4.542

Kleindorfer S, Peters KJ, Hohl L, Sulloway FJ (2016) Flight behaviour of an introduced parasite affects its Galapagos Island hosts: Philornis downsi and Darwin's finches. In: Weis DS (ed) Judith S. Biological Invasions and Animal Behaviour. Cambridge University Press, Cambridge, pp 158-179

Kleindorfer S, Sulloway FJ (2016) Naris deformation in Darwin's finches: experimental and historical evidence for a post-1960s arrival of the parasite Philornis downsi. Global Ecology and Conservation 7:122-131. https://doi.org/10.1016/j.gecco.2016.05.006

Lahuatte PF, Lincango MP, Heimpel GE, Causton CE (2016) Rearing larvae of the avian nest parasite, Philornis downsi (Diptera: Muscidae), on chicken blood-based diets. Journal of Insect Science 16(1) doi:https://doi.org/10.1093/jisesa/iew064

Lawson LP et al (2017) Slow motion extinction: inbreeding, introgression, and loss in the critically endangered mangrove finch (Camarhynchus heliobates). Conserv Genet 18(1):159-170. https://doi. org/10.1007/s10592-016-0890-x

Lincango P, Causton C (2009) Ensayos de atrayentes para la captura de la mosca parásito, Philornis downsi (Diptera: Muscidae) en las Islas Galápagos. Puerto Ayora, Galapagos, Ecuador: Charles Darwin Foundation

Lincango P, Causton C, Cedeño D, Castañeda J, Hillstrom A, Freund D (2015) Interactions between the Avian Parasite, Philornis downsi (Diptera: Muscidae) and the Galapagos Flycatcher, Myiarchus magnirostris Gould (Passeriformes: Tyrannidae). J Wildl Dis 51(4):907-910. https://doi.org/10.7589/2015-01-025

Lyons CL, Coetzee M, Terblanche JS, Chown SL (2014) Desiccation tolerance as a function of age, sex, humidity and temperature in adults of the African malaria vectors Anopheles arabiensis and Anopheles funestus. J Exp Biol 217(21):3823. https://doi.org/10. 1242/jeb. 104638

Mathieu-Bégné E, Loot G, Mazé-Guilmo E, Mullet V, Genthon C, Blanchet S (2020) Combining species distribution models and population genomics underlines the determinants of range limitation in an emerging parasite. Ecography 44(2):307-319. https:// doi.org/10.1111/ecog.05301

Maxwell SM et al (2019) Seasonal spatial segregation in blue sharks (Prionace glauca) by sex and size class in the Northeast Pacific Ocean. Divers Distrib 25(8):1304-1317. https://doi.org/10.1111/ ddi. 12941

McNew SM, Clayton DH (2018) Alien invasion: Biology of Philornis flies highlighting Philornis downsi, an introduced parasite of Galápagos birds. Annu Rev Entomol 63(1):369-387. https://doi. org/10.1146/annurev-ento-020117-043103

Midgarden D, Lira E, Silver M (2014) Spatial Analysis of tephritid fruit fly traps. In: Shelly T, Epsky N, Jang EB, Reyes-Flores J, 
Vargas R (eds) Trapping and the Detection, Control, and Regulation of Tephritid Fruit Flies: Lures, Area-Wide Programs, and Trade Implications. Springer, Netherlands, Dordrecht, pp 277-320

Miller TEX, Inouye BD (2013) Sex and stochasticity affect range expansion of experimental invasions. Ecol Lett 16(3):354-361. https://doi.org/10.1111/ele.12049

NOAA (2016) World Vector Shorelines. NOAA Shoreline Website. https://shoreline.noaa.gov/data/datasheets/wvs.html. Accessed 4 Dec 2020

O'Connor JA, Robertson J, Kleindorfer S (2010a) Video analysis of host-parasite interactions in nests of Darwin's finches. Oryx 44(4):588-594. https://doi.org/10.1017/S0030605310000086

O'Connor JA, Sulloway FJ, Robertson J, Kleindorfer S (2010b) Philornis downsi parasitism is the primary cause of nestling mortality in the critically endangered Darwin's medium tree finch (Camarhynchus pauper). Biodivers Conserv 19(3):853-866. https://doi. org/10.1007/s10531-009-9740-1

Olson DH et al (2013) Mapping the Global Emergence of Batrachochytrium dendrobatidis, the Amphibian Chytrid Fungus. PLoS ONE 8(2):e56802. https://doi.org/10.1371/journal.pone.0056802

Oorebeek M, Kleindorfer S (2008) Climate or host availability: what determines the seasonal abundance of ticks? Parasitol Res 103(4):871. https://doi.org/10.1007/s00436-008-1071-8

Papadopoulos NT, Katsoyannos BI, Nestle D (2003) Spatial autocorrelation analysis of a Ceratitis capitata (Diptera: Tephritidae) adult population in a mixed deciduous fruit orchard in Northern Greece. Environ Entomol 32(2):319-326. https://doi.org/10.1603/ 0046-225X-32.2.319

Papathanos PA, Windbichler N, Akbari OS (2014) Sex ratio manipulation for insect population control. Transgenic Insects: Techniques and Applications 83:100

Parker G (1978) Evolution of competitive mate searching. Annu Rev Entomol 23(1):173-196

Pelletier F, Coltman DW (2018) Will human influences on evolutionary dynamics in the wild pervade the Anthropocene? BMC Biol 16(1):7. https://doi.org/10.1186/s12915-017-0476-1

Preston-Mafham K (2001) Resource defence mating system in two flies from Sulawesi: Gymnonerius fuscus Wiedemann and Telostylinus sp. near duplicatus Wiedemann (Diptera: Neriidae). Journal of Natural History 35(1):149-156 doi:https://doi.org/10.1080/00222 9301447916

R Core Development Team (2020) R: A language and environment for statistical computing. R version 4.0.0. R Foundation for Statistical Computing, Vienna, Austria

Raghavan RK et al (2019) Potential spatial distribution of the newly introduced long-horned tick, Haemaphysalis longicornis in North America. Sci Rep 9(1):498. https://doi.org/10.1038/ s41598-018-37205-2

Romey WL, Wallace AC (2007) Sex and the selfish herd: sexual segregation within nonmating whirligig groups. Behav Ecol 18(5):910 915. https://doi.org/10.1093/beheco/arm057

Roswell M, Dushoff J, Winfree R (2019) Male and female bees show large differences in floral preference. PLoS ONE 14(4):e0214909. https://doi.org/10.1371/journal.pone.0214909

Ruberanziza E et al (2019) Mapping soil-transmitted helminth parasite infection in Rwanda: estimating endemicity and identifying at-risk populations. Tropical Medicine and Infectious Disease 4(2):93

Ruckstuhl K, Neuhaus P (2006) Sexual segregation in vertebrates. Cambridge University Press, Cambridge

Sakai AK et al (2001) The population biology of invasive species. Annu Rev Ecol Syst 32(1):305-332. https://doi.org/10.1146/annur ev.ecolsys.32.081501.114037

Sciarretta A, Tabilio MR, Lampazzi E, Ceccaroli C, Colacci M, Trematerra P (2018) Analysis of the Mediterranean fruit fly [Ceratitis capitata (Wiedemann)] spatio-temporal distribution in relation to sex and female mating status for precision IPM. PLoS ONE 13(4):e0195097. https://doi.org/10.1371/journal.pone.0195097

Skidmore P (1985) The biology of the Muscidae of the world, vol 29. Springer Science \& Business Media, Dordrecht

Souris M (2018) Ecuador. Institut de Recherche pour le Développement, IRD. http://www.savgis.org/ecuador.htm 2021. Accessed 4 Dec 2021

Stanley CR, Liddiard Williams H, Preziosi RF (2018) Female clustering in cockroach aggregations-a case of social niche construction? Ethology 124(10):706-718. https://doi.org/10.1111/eth. 12799

Stone GN (1995) Female foraging responses to sexual harassment in the solitary bee Anthophora plumipes. Anim Behav 50(2):405412. https://doi.org/10.1006/anbe.1995.0255

Vargas RI, Leblanc L, Piñero JC, Hoffman KM (2014) Male annihilation, past, present, and future. In: Shelly T, Epsky N, Jang EB, Reyes-Flores J, Vargas R (eds) Trapping and the Detection, Control, and Regulation of Tephritid Fruit Flies: Lures, AreaWide Programs, and Trade Implications. Springer, Netherlands, Dordrecht, pp 493-511

Warburg MS, Yuval B (1997) Circadian patterns of feeding and reproductive activities of Mediterranean fruit flies (Diptera: Tephritidae) on various hosts in Israel. Ann Entomol Soc Am 90(4):487495. https://doi.org/10.1093/aesa/90.4.487

Wessel P, Smith WHF (1996) A global, self-consistent, hierarchical, high-resolution shoreline database. Journal of Geophysical Research: Solid Earth 101(B4):8741-8743. https://doi.org/10. 1029/96JB00104

Wiedenfeld DA, Jiménez GU, Fessl B, Kleindorfer S, Carlos Valarezo J (2007) Distribution of the introduced parasitic fly Philornis downsi (Diptera, Muscidae) in the Galápagos Islands. Pac Conserv Biol 13(1):14-19. https://doi.org/10.1071/PC070014

Wilkinson GS, Johns PM (2005) Sexual selection and the evolution of mating systems in flies. In: Yeates DK, Weigmann BM (eds) The Biology of the Diptera. Columbia University Press, New York, pp 312-329

Wong GKL, Jim CY (2018) Abundance of urban male mosquitoes by green infrastructure types: implications for landscape design and vector management. Landscape Ecol 33(3):475-489. https://doi. org/10.1007/s10980-018-0616-1

Woodworth BL et al (2005) Host population persistence in the face of introduced vector-borne diseases: Hawaii amakihi and avian malaria. Proc Natl Acad Sci USA 102(5):1531. https://doi.org/ 10.1073/pnas.0409454102

Yamagishi M, et al. 1993 Eradication of the melon fly from Okinawa, Japan, by means of the sterile insect technique. Management of Insect Pests: Nuclear and Related Molecular and Genetic Techniques.

Yeates D, Dodson G (1990) The mating system of a bee fly (Diptera: Bombyliidae). II. Factors affecting male territorial and mating success. J Insect Behav 3(5):619-636. https://doi.org/10.1007/ BF01052332

Young HS et al (2015) Drivers of intensity and prevalence of flea parasitism on small mammals in East African savanna ecosystems. J Parasitol 101(3):327-335. https://doi.org/10.1645/14-684.1

Yuval B (2005) Mating systems of blood-feeding flies. Annu Rev Entomol 51(1):413-440. https://doi.org/10.1146/annurev.ento. 51.110104 .151058

Publisher's note Springer Nature remains neutral with regard to jurisdictional claims in published maps and institutional affiliations. 